\title{
A Review on Geopolymer RCC Beams made with Recycled Coarse Aggregate
}

\author{
Srinivas. $\mathrm{T}^{1}$, Abhignya. $\mathrm{G}^{2}$ and Ramana Rao. N. $\mathrm{V}^{3}$
}

${ }^{1}$ Professor, Department of Civil Engineering, GRIET, Hyderabad, India.

${ }^{2}$ M. Tech Structural Engineering Student, GRIET, Hyderabad, India.

${ }^{3}$ Professor, Department of Civil Engineering, JNTUH, Hyderabad, India.

\begin{abstract}
In present day scenario, concrete construction is rapidly increasing for different uses and aspects irrespective of the economy and its usage. Due to this imbalanced usage of economy, scarcity of raw materials increasing day by day and environment is getting affected due to manufacturing of cement. This study has been done how to reduce environmental pollution by using different kind of bi product materials in replacement to conventional concrete, which is made up of OPC. The cement can be replaced with fly ash; GGBS, rice husk ash etc, aggregates are being partially replaced with recycled aggregates which come from demolished structures and alkaline liquids such as sodium silicates and sodium hydroxide can be used in concrete, which is called geopolymer concrete. Literature review has been carried out to find the optimum content of aggregates to be replaced and the flexure behavior of the beams is being evaluated. From the literature study, it has been identified that the optimum compressive strength is achieved at $30 \%$ replacement of recycled aggregate and ductility natures of both Geopolymer and conventional concrete beams are almost similar.
\end{abstract}

\footnotetext{
${ }^{1}$ Corresponding Author Email: srinu.tummala@gmail.com
} 


\section{INTRODUCTION}

Concrete is the most generally used construction material within the world. Ordinary Portland cement (OPC) has been traditionally used because the binding material for concrete. "The manufacturing of OPC requires the burning of enormous quantities of fossil fuels and decomposition of limestone which ends up in significant emissions of carbon-di-oxide $\mathrm{CO}_{2}$ to the atmosphere. This $\mathrm{CO}_{2}$ emission is the main cause for heating, which became a serious concern". To scale back this, Geo polymer technology was introduced.

"The term Geo polymer was utilized by Professor Davidovits in 1978 to explain the inorganic aluminosilicate polymeric gel resulting from reaction of amorphous alumino-silicates with alkali hydroxide and silicate solutions". Unlike ordinary hydraulic cement, Geo polymer don't form calcium silicate hydrates for matrix formation and strength but utilize the poly condensation of silica and alumina to achieve strength. Two main constituents of Geo polymers are source and alkaline liquid. The source material should be aluminosilicate based and rich in both silica and alumina. "In Geo polymer concrete, supplementary cementing materials like Fly ash, Silica fume, Rice Husk ash, Ground Granulated Blast furnace Slag (GGBS) and metakaolin are used as alternative binders to hydraulic cement, during this project, Fly ash and Ground Granulated furnace Slag (GGBS) are used as alternative binders".

Geo polymer is a superb alternative material which transforms industrial waste products like GGBS and ash into binder for concrete. "Geo polymer binders are used along with aggregates to provide Geo polymer concrete. They are ideal for building and repairing infrastructures and for pre-casting units, because they need very high early strength". Their setting times may be controlled and that they remain intact for very long time without any need for repair. Geo polymer, with properties like abundant raw resource, little $\mathrm{CO}_{2}$ emission, less energy consumption, low cost, high early strength and fast setting.

\subsection{Advantages}

- Cutting the worlds carbon

- Cost of Fly ash is low

- Better compressive strength

- Low permeability, creep and shrinkage

- Eco-friendly and resistance to heat and cold

- Excellent properties within both acid and salt environment

\subsection{Disadvantages}

- It is difficult to create and requires special handling
- Lacks uniformity

- Prepolymerization is sensitive

\section{LITERATURE REVIEW}

The research of geopolymer concrete has extended from structural materials such as cubes and cylinders to structural elements such as beams, columns and slabs. From the research, it was found that the behavior of structural elements of geopolymer concrete shows much strength when compared with conventional concrete.

Chau-khun ma et al. [1] "concluded that the replacement of coarse aggregates with recycled aggregates and by replacing cement with many by-products gives much strength reducing in greenhouse gases and have better structural properties compared with conventional concrete".

Ngoc Kien Bui et al. [2] "says that properties of untreated recycled aggregate concrete by using sodium silicate and silica fume shows that, compressive strength can gain strength up to $33-50 \%$, split tensile strength to $33-41 \%$ and they also concluded that the strengths at early stages are relatedly at low but increases gradually in later stages".

Deepa Raj S et al. [3] "have conducted many experiments to find the optimum percentage of recycled aggregates and found that an optimum replacement of $40 \%$ recycled aggregates shows good workability and properties". "They also concluded that strength behavior is more compared with conventional concrete and they recommended as a sustainable and environment friendly construction material".

Saravanakumar [4], "from their study states that the addition of recycled coarse aggregate (RCA) collected from construction and demolition (C\&D) waste good results compared with natural aggregates and reduces the space for landfill. They also said that an increment of $25 \%$ replacement by weight of natural aggregates with recycled aggregates in geopolymer concrete up to $100 \%$ replacements were studied and said that geopolymer based recycled aggregate concrete exhibits better strength and durability performance that ordinary recycled aggregate concrete".

Preethy K Thomas et al [5]. "states that low calcium fly ash and alkaline liquid as binder is being used to replace the Portland cement to produce geopolymer concrete, which is one of the methods to reduce environmental pollution". "The alkaline liquid that has been used in geopolymerisation is the combination of sodium hydroxide $(\mathrm{NaOH})$ and sodium silicate $\left(\mathrm{Na}_{2} \mathrm{SiO}_{3}\right)$, which also involves to know the possibility to replace natural coarse aggregates with recycled aggregates in 
geopolymer concrete and the structural characteristics of geopolymer concrete with different molar ratios of $\mathrm{NaOH}$ like $8 \mathrm{M}, 10 \mathrm{M}$ and $12 \mathrm{M}$ were taken into consideration and the development of compressive strength, split tensile strength and flexural strength at the age of $3,7 \& 28$ days were studied after oven curing at $800 \mathrm{C}$ and concluded that environment pollution is reduced by decreasing the landfill area and saving natural aggregates".

Sanjay $\mathrm{R}$ et al [6]. "studied that utilization of the industrial by-products and construction \& demolition waste in the synthesis of geopolymer concrete, comprising of flyash and Ground Granulated Blast Furnace slag (GGBS) weregeopolymerised by sodium silicate and sodium hydroxide $(\mathrm{NaOH})$ solution and recycled aggregate were completely replaced the coarse aggregates in geopolymer concrete and the specimens were tested on the $7^{\text {th }}$ day after casting". As the compressive strength was found to increase with the increase in $\mathrm{NaOH}$ molarity, an optimum molarity of $12 \mathrm{M}$ was adopted. "Their experimental investigations showed that the inclusion of GGBS by $10 \%$ mass in the binder material increased the compressive strength by $23 \%$ and the effects of variation of binder percentage on workability, compressive strength, flexural strength and split tensile strength were analyzed". Results obtained were (fly ash + GGBS) $27 \%$ of the total solid constituents. "Adopting $27 \%$ of the binder content with $12 \mathrm{M} \mathrm{NaOH}$ molarity, beams were casted and tested for the load deflection behavior, ultimate load and crack width".

Kumaravel et al [7]. stated that the production of Ordinary Portland Cement (OPC) causes environmental pollution. "As an alternative, other materials like low calcium fly ash based by-product from coal industry which is rich in silicate and alumina reacts with alkaline solution to produce alumino-silicate gel which binds the aggregate to produce a good concrete is used". "As a result compressive strength increases with increase in fly ash and flexural behavior of geopolymer beams were studied". "Results shown that geopolymer concrete beams exhibit increased flexural strength and deflections at different stages including service load and peak load stage are higher for GPC beams".

"Several people concluded that using fly ash in replacement of cement and recycled aggregates in place of natural aggregates says that the geopolymer concrete columns is much better than RC columns up to $37 \%$ in ultimate strength and the inclusion of steel fibers increased the load carrying capacity by up to $50 \%$ ".

Rajendran et al [10]. "have concluded that by using byproducts the enhanced ductility and energy absorption can increase the volume and improves the impact energy absorption about 10 times".

\section{MATERIALS AND MIX DESIGN}

\subsection{Materials}

\subsubsection{Coarse aggregates}

"Coarse aggregates obtained locally with size of $20 \mathrm{~mm}$ are used for the study confirming to IS: $383-1970$, the physical properties of natural coarse aggregate area tested in accordance with IS:2386-1963".

\subsubsection{Recycled aggregates}

"Recycled aggregate were used as the coarse aggregate in the concrete mixtures of this study, construction and demolition waste contributes up to 40 percent of all waste generated across the world". Recycled aggregates are obtained from the construction and demolition waste.

\subsubsection{Fine aggregates}

River sand can be used as fine aggregates confirming to IS: $383-1970$.

\subsubsection{Fly ash}

A by-product of coal is taken as class F fly ash confirming to IS: $3812-2003$ is used. "Fly ash as a binding material plays a crucial role in geopolymer concrete which is considered as the main constituent with a replacement of $85 \%$ of cement in geopolymer concrete".

\subsubsection{GGBS}

"Ground granulated blast furnace slag (GGBS) is a by-product from the blast furnaces used to make iron". "It is produced when iron is heated at a temperature around $1500^{\circ} \mathrm{C}$, it is eco friendly material, GGBS replaced around $15 \%$ by mass of binder in Geopolymer concrete".

\subsubsection{Cement}

Ordinary Portland Cement (OPC) is a primary binder in the controlled concrete. "The physical properties of cement were confirmed to specifications of IS 269-2015".

\subsection{Alkaline solution}

"From various studies and trail mixes the alkaline solution is the combination of sodium silicate and sodium hydroxide solutions which leads to high strength of concrete mix in geopolymer concrete". "Sodium silicate plays a 
major role in polymerization process in GPC, sodium hydroxide is used in the form of pellets which are dissolved with sodium silicate solution to attain the alkaline solution". Combination of these chemicals gives the concentration and molarity for activating the solution.

\subsection{Super plasticizers}

To enhance the workability of Geo polymer concrete, high range water reducing superplasticizer was used. "Use of super-plasticizer also reduces the first setting time of concrete which successively improve the mechanical behavior of GPC". A naphtha based superplasticizer called naphthalene sulphonate formaldehyde is employed for acquiring better strength.

\subsection{Mix design}

Mix design is done as per the Indian standards IS: $10262-2009$ for both conventional and geopolymer concrete.

\section{CONCLUSIONS}

From the literature it has been observed that:

Several researchers concluded that using fly ash and GGBS in place of cement and recycled aggregates in place of natural aggregates, the geopolymer concrete beams and columns are much better than Conventional RCC beams and columns in terms of compressive and flexural strengths.

It has been identified that the optimum compressive strength is achieved at $30 \%$ replacement of recycled aggregate and ductility natures of both Geopolymer and conventional concrete beams are almost similar.

Many researchers had shown that the geopolymer concrete is a good engineering material for future work, since it is eco-friendly material.

\section{References}

1. Chau-Khun M, Abdullah ZawawiAwang, Wahid Omar, "Structural and material performance of geopolymer concrete", ELSEVIER 186 ,90-102, (2018)

2. Ngoc Kien Bui, Tomoaki Satomi, Hiroshi Takahashi, "Mechanical properties of concrete containing $100 \%$ treated coarse recycled concrete aggregate" ELSEVIER 163 496-507, (2018).

3. Deepa Raj S, JithinBhoopesh(2017), "Strength and behaviour of recycled aggregate geopolymer concrete beams" Advances in Concrete Construction: Vol. 5, No. 2, 145-154, (2017).
4. P. Saravanakumar, "Strength and Durability Studies on Geopolymer Recycled Aggregate Concrete", IJET 7 (2.24), 370-375, (2018).

5. Anchula Nagarjuna, T. Suresh Kumar, B.Yogeswara Reddy, M.Udaykiran, International Journal of Innovative Technology and Exploring Engineering, Vol. 8 no. 11, pp: 640-645, (2019)

6. Sanjay R, Dr. M. U. Aswath, Smita Singh, " $A n$ Experimental Study on Flexural Behaviour of Reinforced Geopolymer Concrete Beams with Recycled Aggregate in Bending", Research Gate: Issue 2, Vol.6 ISSN 2249-6149. (2012)

7. S.Kumaravel, Thirugnanasambandam, "Flexural Behaviour Of Geopolymer Concrete Beams", research paper E-ISSN2249-8974 (2013)

8. T. Sujatha, K. Kannapiran, S. Nagan, "Strength assessment of heat cured geopolymer concrete slender column", Asian J. Civil Eng. 13 (5) 635646, (2012).

9. Naspuri Arun Raju, T. Suresh Kumar, International Journal of Innovative Technology and Exploring Engineering, Vol. 8 no. 11, pp: 3860-3864, (2019).

10. M. Rajendran, N. Soundarapandian, "An experimental investigation on the flexural behavior of geopolymer ferrocement slabs", J. Eng. Technol. 3 (2) (2013).

11. S. Nagan, R. Mohana, "Behaviour of geopolymer ferrocement slabs subjected to impact", Iranian J. Sci. Technol. Trans. Civil Eng. $38(\mathrm{C} 1+), 223$ (2014).

12. Sateesh, N., Sampath Rao, P., Ravishanker, D.V., Satyanarayana, K., "Effect of Moisture on GFRP Composite Materials", Materials Today: Proceedings, 2 (4-5), pp. 2902-2908, (2015).

13. Srinivasa Reddy, V., Seshagiri Rao, M.V., Shrihari, $\mathrm{S}$, "Appraisal of processing techniques for recycled aggregates in concrete", IJEAT, 8 (6), pp. 16611665, (2019).

14. Reddy, V.M., Manikanta, S, "Mechanical properties of fibre reinforced self compacting concrete using rice husk ash", IJRTE, 8 (3), pp. 6412-6415, (2019).

15. Satyanarayana, G.V.V., Saikiran, C.H, “ Effect on mechanical properties of M35 grade concrete by partial replacement of fine aggregate with copper slag”, IJITEE, 8 (12), pp 3759-3762. 